\title{
Leisure-Time Physical Activity and the Risk of Incident Dementia: The Mayo Clinic Study of Aging
}

\author{
Janina Krell-Roesch ${ }^{\mathrm{a}}$, Nathanael T. Feder ${ }^{1}$, Rosebud O. Roberts ${ }^{\mathrm{b}, \mathrm{c}}$, Michelle M. Mielke ${ }^{\mathrm{b}, \mathrm{c}}$, \\ Teresa J. Christianson ${ }^{d}$, David S. Knopman ${ }^{\mathrm{c}}$, Ronald C. Petersen ${ }^{\mathrm{b}, \mathrm{c}}$ and Yonas E. Geda ${ }^{\mathrm{a}, \mathrm{b}, \mathrm{e}, \mathrm{f}, *}$ \\ ${ }^{a}$ Translational Neuroscience and Aging Program, Mayo Clinic, Scottsdale, AZ, USA \\ ${ }^{\mathrm{b}}$ Department of Health Sciences Research, Division of Epidemiology, Mayo Clinic, Rochester, MN, USA \\ ${ }^{\mathrm{c}}$ Department of Neurology, Mayo Clinic, Rochester, MN, USA \\ ${ }^{\mathrm{d}}$ Department of Health Sciences Research, Division of Biomedical Statistics and Informatics, Mayo Clinic, \\ Rochester, MN, USA \\ ${ }^{\mathrm{e}}$ Department of Neurology, Mayo Clinic, Scottsdale, AZ, USA \\ ${ }^{\mathrm{f}}$ Department of Psychiatry and Psychology, Mayo Clinic, Scottsdale, AZ, USA
}

Accepted 22 January 2018

\begin{abstract}
We conducted a prospective cohort study derived from the population-based Mayo Clinic Study of Aging. We investigated if leisure-time physical activity among individuals with mild cognitive impairment (MCI) was associated with a decreased risk of developing dementia. 280 persons aged $\geq 70$ years (median 81 years, 165 males) with MCI and available data from neurologic evaluation, neuropsychological testing, and questionnaire-based physical activity assessment, were followed for a median of 3 years to the outcomes of incident dementia or censoring variables. We conducted Cox proportional hazards regression analyses with age as a time scale and adjusted for sex, education, medical comorbidity, depression, and APOE $\varepsilon 4$ status. Moderate intensity midlife physical activity among MCI participants was significantly associated with a decreased risk of incident dementia $(\mathrm{HR}=0.64 ; 95 \% \mathrm{CI}, 0.41-0.98)$. There was a non-significant trend for a decreased risk of dementia for light and vigorous intensity midlife physical activity, as well as light and moderate intensity late-life physical activity. In conclusion, we observed that physical activity may be associated with a reduced risk of dementia among individuals with MCI. Furthermore, intensity and timing of physical activity may be important factors when investigating this association.
\end{abstract}

Keywords: APOE $\varepsilon 4$, cohort study, incident dementia, mild cognitive impairment, physical activity

\section{INTRODUCTION}

Observational and interventional studies have indicated that physical activity could potentially decrease the risk for dementia, even among persons with cognitive impairment [1-11]. Recently, two prominent

\footnotetext{
${ }^{1}$ N.T. Feder is a medical student at the University of Groningen who did his thesis work under mentorship of Professor Geda at Mayo Clinic in Scottsdale, Arizona.

*Correspondence to: Yonas E. Geda, MD, MSc, Mayo Clinic, 13400 E. Shea Blvd., Scottsdale, AZ 85259, USA. Tel.: +1 480 301 4343; E-mail: geda.yonas@mayo.edu.
}

expert panels, i.e., the Committee on Preventing Dementia and Cognitive Impairment of the National Academy of Sciences [12] and the Lancet Commission on Dementia Prevention, Intervention, and Care [13], underlined the potential beneficial effect of physical activity in preventing or delaying dementia. However, not all studies are supportive of the conclusions of the expert panels $[14,15]$. We recently reported an association between physical activity (with an emphasis on timing of engaging, i.e., midlife versus late-life physical activity) and the risk of incident mild cognitive impairment (MCI), which is an 
intermediate stage between normal cognitive aging and dementia [16]. Despite a large body of research that has been published on the association between physical activity and dementia, little is known about the association between timing of engaging in physical activity (midlife versus late-life) and the risk of new onset of dementia among persons with prevalent MCI.

Therefore, we conducted this prospective cohort study derived from the population-based Mayo Clinic Study of Aging to investigate the association between three different intensity levels of midlife and late-life physical activity and the risk of incident dementia. Additionally, we examined 1) whether there was an interaction between midlife and late-life physical activity in relation to risk of incident dementia; and 2) whether dementia-related confounding variables such as medical comorbidities, depression, and APOE $\varepsilon 4$ genotype status impact the association.

\section{MATERIALS AND METHODS}

\section{Design and sample}

This prospective cohort study was derived from the ongoing, population-based Mayo Clinic Study of Aging (MCSA) in Olmsted County, Minnesota. The reader is referred to a detailed description of the design and conduct of the MCSA that has been reported elsewhere [17]. We prospectively followed a cohort of 280 participants aged 70 years and older who had MCI at baseline for a median of 3.0 years (interquartile range [IQR]: 2.5, 5.3) to the outcomes of incident dementia or censoring variables (Fig. 1). The institutional review boards of the Mayo Clinic and Olmsted Medical Center in Rochester, MN approved the MCSA protocols. All study participants provided written informed consent.

\section{Measurement of leisure-time physical activity}

Leisure-time physical activity was measured using a self-reported questionnaire [18] based on questions from validated instruments: the 1985 National Health Interview Survey [19], and the Minnesota Heart Survey intensity codes [20]. The questionnaire assessed the intensity and frequency of physical activity at two time periods: 1) in late-life, i.e., performed within one year prior to cognitive assessment; and 2) in midlife, i.e., performed between the ages of 50 and 65 years. The questionnaire distinguished between three intensity levels of physical activity: 1) light intensity such

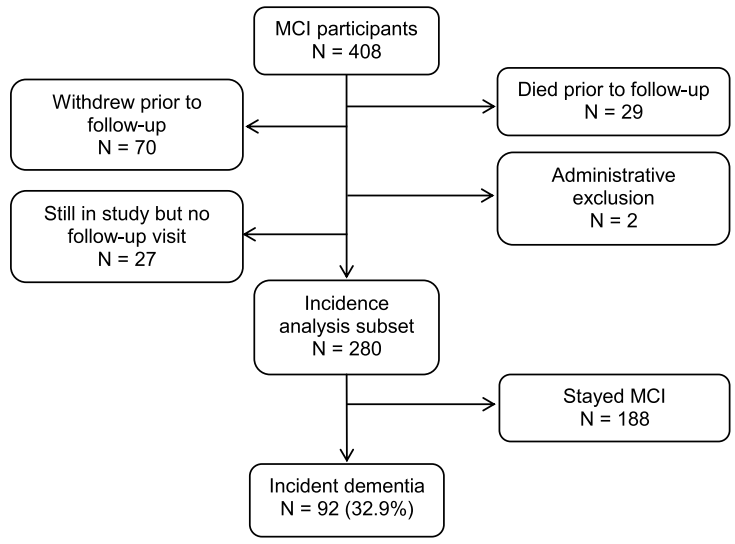

Fig. 1. Study flowchart.

as walking or stretching, 2) moderate intensity such as hiking or swimming, and 3) vigorous intensity such as tennis single, jogging, or skiing. Participants also provided information about the frequency of activity: $\leq 1$ time per month, 2-3 times per month, 1-2 times per week, 3-4 times per week, 5-6 times per week, and daily.

\section{Diagnosis of MCI and dementia}

Participants underwent a face-to-face evaluation including a neurological examination, a risk factors ascertainment, and extensive neuropsychological testing. The reader is referred elsewhere for details on the face-to-face evaluation [17]. Briefly, the neurological evaluation comprised a neurological history review, administration of Short Test of Mental Status [21], and a neurological examination. The risk factor assessment interview was conducted by a nurse or study coordinator and included the Clinical Dementia Rating Scale (CDR). Lastly, neuropsychological testing was administered by a psychometrist in order to assess performance in four cognitive domains: memory (delayed recall trials from Auditory Verbal Learning Test [22], Wechsler Memory Scale-Revised [23], Logical Memory and Visual Reproduction subtests), language (Boston Naming Test [24], category fluency [25]); visuospatial skills (Wechsler Adult Intelligence Scale-Revised [26], Picture Completion and Block Design subtests); and executive function (Trail-Making Test Part B [27], Wechsler Adult Intelligent Scale-Revised [26], Digit Symbol Substitution subtest). An expert consensus panel consisting of physicians, study nurses and neuropsychologists reviewed and evaluated the results for each participant and made a diagnosis of MCI or dementia. The 
clinical diagnosis of MCI was made based on the published Mayo Clinic criteria [28, 29]. Dementia was diagnosed according to DSM-IV criteria [17].

\section{Assessment of confounders}

Medical comorbidity was assessed using the weighted Charlson Index [30]. Depression was measured using Beck Depression Inventory-II [31]. APOE $\varepsilon 4$ genotype status was determined using standard methods [32].

\section{Statistical analysis}

We calculated hazard ratios (HR) and 95\% confidence intervals $(95 \% \mathrm{CI}$ ) using the Cox proportional hazards model, with age as a time scale. The models were adjusted for traditional confounders (sex and education). Furthermore, in line with our research question, we also adjusted for medical comorbidity, depression, and APOE $\varepsilon 4$ status. Analyses were conducted separately for physical activity in midlife (aged 50-65) and late-life (within 1 year of the cognitive assessment) and for the three different levels of intensity (light, moderate, and vigorous). Any physical activity (defined as engaging in physical activity at least 2-3 times per month) was compared to none (reference; defined as physical activity once per month or less). Lastly, we also investigated possible interaction effects between light and moderate intensity physical activity in mid- and late-life and the risk of incident dementia by using multivariate models. The statistical analyses were done using the conventional two-tailed alpha level of 0.05 and performed with SAS (SAS Institute, Inc., Cary, NC).

\section{RESULTS}

Of 280 participants (165 males) with MCI at baseline, 92 developed incident dementia at follow-up. At baseline, the median age of the cohort was 81 years (IQR: 76, 85) and the median level of education was 12 years (IQR: 12, 15). Please refer to Table 1 for an overview of demographic data.

After adjusting for age, sex, and education, moderate intensity physical activity in midlife $(\mathrm{HR}=0.64$; 95\% CI, 0.41-0.98) was significantly associated with a decreased risk of incident dementia (Table 2). When we additionally adjusted for medical comorbidity, depression, and APOE $\varepsilon 4$ carrier status, the association remained no longer significant. In addition, neither midlife light intensity $(\mathrm{HR}=0.59 ; 95 \%$
Table 1

Demographic characteristics of participants with prevalent MCI at baseline

\begin{tabular}{lc}
\hline Variable & MCI $(\mathrm{N}=280)$ \\
& $\mathrm{N}(\%)$ \\
\hline Males & $165(58.9)$ \\
Age, $\mathrm{y}^{\mathrm{a}}$ & $81[76,85]$ \\
$70-79$ & $111(39.6)$ \\
$80-94$ & $169(60.4)$ \\
Education, $\mathrm{y}^{\mathrm{a}}$ & $12[12,15]$ \\
$>_{12}$ years & $125(44.6)$ \\
BDI-II, total score ${ }^{\mathrm{a}}$ & $5[2,9]^{(1)}$ \\
Depression (total score $\geq 13)$ & $38(13.6)$ \\
Number of medical comorbidities & $\mathrm{a}$ \\
APOE $\varepsilon 4$ carrier & $4[3,7]$ \\
Late-life activity & $98(35.1)^{(1)}$ \\
Light & \\
Moderate & $215(76.8)$ \\
Vigorous & $137(48.9)$ \\
Midlife activity & $33(11.8)$ \\
Light & \\
Moderate & $243(86.8)$ \\
Vigorous & $193(68.9)$ \\
Follow-up, $\mathrm{y}^{\mathrm{a}}$ & $84(30.0)$ \\
\hline
\end{tabular}

MCI, mild cognitive impairment; BDI-II, Beck Depression Inventory-II. Physical activity: carried out 2-3 times per month or

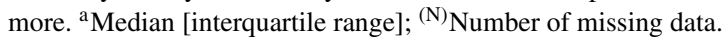

CI, 0.33-1.04) nor midlife vigorous intensity physical activity $(\mathrm{HR}=0.62 ; 95 \% \mathrm{CI}, 0.38-1.02)$ were associated with the risk of dementia. Similarly, physical activity within the past year (i.e., late-life), be it light (HR $=0.89$; 95\% CI, 0.54-1.46), moderate $(\mathrm{HR}=0.93 ; 95 \% \mathrm{CI}, 0.60-1.43)$, or vigorous $(\mathrm{HR}=1.34 ; 95 \% \mathrm{CI}, 0.71-2.51)$, was not associated with the risk of incident dementia. However, in general, all point estimates with the exception of vigorous late-life physical activity were below 1.0 suggesting a protective, though non-significant effect of physical activity against dementia (Table 2).

Finally, results from the multivariate model analyses revealed that participants who engaged in both midlife and late-life physical activity combined (light intensity: $\mathrm{HR}=0.83 ; 95 \% \mathrm{CI}, 0.37-1.88$; moderate intensity: $\mathrm{HR}=0.72 ; 95 \% \mathrm{CI}, 0.42-1.23$ ) and those who engaged only in midlife but not late-life physical activity (light intensity: $\mathrm{HR}=1.02 ; 95 \% \mathrm{CI}$, 0.41-2.56; moderate intensity: $\mathrm{HR}=0.67 ; 95 \% \mathrm{CI}$, $0.38-1.20$ ) had lower point estimates than participants who reported engaging only in late-life but not midlife physical activity (light intensity: $\mathrm{HR}=2.64$; 95\% CI, 0.90-7.75; moderate intensity: $\mathrm{HR}=1.18$; 95\% CI, 0.54-2.59). We defined the reference group $(\mathrm{HR}=1.00)$ as participants who did not report engaging in physical activity in mid- or late-life. However, 
Table 2

Midlife and late-life physical activity and the risk of incident dementia

\begin{tabular}{|c|c|c|}
\hline Variable & $\mathrm{HR}(95 \% \mathrm{CI})$ & $p$ \\
\hline \multicolumn{3}{|c|}{ Late-life physical activity } \\
\hline \multicolumn{3}{|c|}{ Adjusted for age, sex, education } \\
\hline Light & $0.89(0.54,1.46)$ & 0.64 \\
\hline Moderate & $0.93(0.60,1.43)$ & 0.73 \\
\hline Vigorous & $1.34(0.71,2.51)$ & 0.37 \\
\hline \multicolumn{3}{|c|}{ Additionally adjusted for medical comorbidities, depression } \\
\hline Light & $0.90(0.55,1.49)$ & 0.69 \\
\hline Moderate & $0.97(0.62,1.51)$ & 0.89 \\
\hline Vigorous & $1.42(0.75,2.70)$ & 0.28 \\
\hline \multicolumn{3}{|c|}{ Additionally adjusted for APOE $\varepsilon 4$ carrier status } \\
\hline Light & $0.91(0.55,1.50)$ & 0.70 \\
\hline Moderate & $0.97(0.63,1.51)$ & 0.91 \\
\hline Vigorous & $1.47(0.77,2.79)$ & 0.24 \\
\hline \multicolumn{3}{|c|}{ Midlife physical activity } \\
\hline \multicolumn{3}{|c|}{ Adjusted for age, sex, education } \\
\hline Light & $0.59(0.33,1.04)$ & 0.07 \\
\hline Moderate & $0.64(0.41,0.98)$ & 0.042 \\
\hline Vigorous & $0.62(0.38,1.02)$ & 0.06 \\
\hline \multicolumn{3}{|c|}{ Additionally adjusted for medical comorbidities, depression } \\
\hline Light & $0.58(0.33,1.05)$ & 0.07 \\
\hline Moderate & $0.67(0.43,1.03)$ & 0.07 \\
\hline Vigorous & $0.67(0.41,1.11)$ & 0.12 \\
\hline \multicolumn{3}{|c|}{ Additionally adjusted for APOE $\varepsilon 4$ carrier status } \\
\hline Light & $0.59(0.33,1.06)$ & 0.08 \\
\hline Moderate & $0.68(0.44,1.05)$ & 0.08 \\
\hline Vigorous & $0.68(0.41,1.12)$ & 0.13 \\
\hline
\end{tabular}

none of these interactions reached statistical significance.

\section{DISCUSSION}

In this population-based cohort of persons with prevalent MCI, moderate intensity physical activity in midlife was associated with a decreased risk of incident dementia, after adjusting for age, sex, and education. Additionally, as indicated by the point estimates (i.e., hazard ratios below 1.0), we observed a non-significant trend for an association between light and vigorous intensity physical activity in midlife and a decreased risk of dementia; as well as between light and moderate intensity physical activity in latelife and a decreased risk of dementia. Furthermore, participants who reported physical activity in both midlife and late-life combined, as compared to other groups, had a decreased risk of incident dementia, though not significant. Adjusting our analyses for dementia-related confounders such as medical comorbidities, depression or APOE $\varepsilon 4$ genotype status did not impact the findings overall; however, the association between moderate intensity midlife physical activity and decreased risk of incident dementia remained no longer significant.

Our study finding is in line with other prospective cohort studies that reported an association between physical activity and decreased risk of dementia [1-11]. For example, investigators from Rush University observed that total daily physical activity as measured by actigraphy was associated with lower risk of incident Alzheimer's disease among persons who were non-demented at baseline, even after adjusting for chronic health conditions, depressive symptoms, and APOE status [1]. Particularly, our study findings imply that leisure-time physical activity intensity and timing, as assessed by selfreported questionnaire, might be important factors that should be considered when examining the association between physical activity and dementia. This confirms a recent report by investigators from Finland and Sweden who showed that low and moderate levels of midlife physical activity were associated with higher risk of dementia as compared to high levels, and that maintaining high levels or increasing levels of physical activity from midlife onwards 
was associated with lower dementia risk [8]. Similarly, a prospective cohort study of investigators from Hong Kong among persons with MCI demonstrated that prolonged physical activity ( $\geq 5$ years) was associated with better cognition at follow-up [33]. However, other studies did not observe an association between physical activity and a decreased risk of dementia. For example, researchers from Europe recently reported that there is no association between physical activity in midlife and the risk of dementia after 27 years of follow-up, based on data from the Whitehall II study [14]. We conducted a cohort study, thus it is difficult to compare our observational study with interventional research findings. Nevertheless, it is worth noting that the LIFE randomized clinical trial showed that a 24-month physical activity intervention did not lead to improved cognitive function among sedentary elderly persons [15]; though this is inconsistent with the modest improvement in cognition after a physical activity intervention reported in JAMA [34].

Given our demonstration that there is an association between moderate intensity midlife physical activity and a decreased risk of incident dementia, we need to understand as to what may account for this relationship. Brain diseases such as neurodegenerative disorders or cerebrovascular disease, even before they are symptomatic, may lead to less motor or physical activity [35]. For instance, Alzheimer's disease is reported to have as long as 20 years of an asymptomatic and prodromal phase. Thus, 'reverse causality' may account for the association between physical activity and decreased risk of incident dementia, i.e., persons with incipient neurodegenerative disease are less likely to engage in physical activity as compared to healthy elderly individuals. Therefore, the ideal observational study would assess the exposure of interest (i.e., physical activity) using an objective technology in midlife and then follow a cohort of cognitively normal persons forward in time and measure the outcome of interest (i.e., incident dementia) several decades later.

The major strength of our study pertains to the setting and design: 1) We conducted the study at a center that has leading expertise in the investigation of MCI; 2) we carried out a prospective cohort study derived from the ongoing, large-scale, populationbased Mayo Clinic Study of Aging. One limitation pertains to the self-reported physical activity questionnaire which may be prone to recall bias. However, we derived the questions from validated instruments (the 1985 National Health Interview Survey, and the
Minnesota Heart Survey intensity codes) [19, 20] and our group has previously reported that the questionnaire has a moderate to good internal consistency as indicated by Cronbach's $\alpha$ of 0.71 [18]. In addition, using a questionnaire enabled us to inquire not only about late-life but also midlife physical activity. Another limitation of our study is that the majority of people residing in Olmsted County are of Caucasian decent. However, it has been shown that data from Olmsted County are generalizable to the U.S. population [36].

In this population-based, prospective cohort study of MCI participants aged 70 years and older, we observed that moderate intensity physical activity in midlife was associated with a decreased risk of new onset of dementia. In addition, the overall data point towards a non-significant trend for an association between physical activity and a decreased risk of incident dementia, except for vigorous physical activity in late-life. Thus, intensity and timing of physical activity may be important factors when investigating the association between physical activity and the risk of dementia. Further research is needed to investigate the direction of causality in this association, i.e., whether physical activity indeed leads to decreased cognitive impairment, or whether incipient cognitive impairment leads to decreased physical activity (reverse causality hypothesis). In addition, future studies should investigate the underlying mechanism of timing and intensity of physical activity and cognitive decline in the elderly; and the association between physical activity and risk of dementia in different ethnic/ racial groups.

\section{ACKNOWLEDGMENTS}

Support for this research was provided by NIH grants: National Institute of Mental Health (K01 MH068351), and National Institute on Aging (U01 AG006786, K01 AG028573, R01AG034676). This project was also supported by the Robert Wood Johnson Foundation, the Robert H. and Clarice Smith and Abigail Van Buren Alzheimer's Disease Research Program, the GHR Foundation, the Edli Foundation, and the Arizona Alzheimer's Consortium. The authors would like to thank Rodrigo Fonseca Portilla for his help with the preparation of the EndNote library.

Authors' disclosures available online (https:// www.j-alz.com/manuscript-disclosures/17-1141r1). 


\section{REFERENCES}

[1] Buchman AS, Boyle PA, Yu L, Shah RC, Wilson RS, Bennett DA (2012) Total daily physical activity and the risk of $\mathrm{AD}$ and cognitive decline in older adults. Neurology 78, 1323-1329.

[2] Grande G, Vanacore N, Maggiore L, Cucumo V, Ghiretti R, Galimberti D, Scarpini E, Mariani C, Clerici F (2014) Physical activity reduces the risk of dementia in mild cognitive impairment subjects: A cohort study. J Alzheimers Dis 39, 833-839.

[3] Laurin D, Verreault R, Lindsay J, MacPherson K, Rockwood K (2001) Physical activity and risk of cognitive impairment and dementia in elderly persons. Arch Neurol 58, 498-504.

[4] Podewils LJ, Guallar E, Kuller LH, Fried LP, Lopez OL, Carlson M, Lyketsos CG (2005) Physical activity, APOE genotype, and dementia risk: Findings from the Cardiovascular Health Cognition Study. Am J Epidemiol 161, 639-651.

[5] Ravaglia G, Forti P, Lucicesare A, Pisacane N, Rietti E, Bianchin M, Dalmonte E (2008) Physical activity and dementia risk in the elderly: Findings from a prospective Italian study. Neurology 70, 1786-1794.

[6] Rovio S, Kareholt I, Helkala EL, Viitanen M, Winblad B, Tuomilehto J, Soininen H, Nissinen A, Kivipelto M (2005) Leisure-time physical activity at midlife and the risk of dementia and Alzheimer's disease. Lancet Neurol 4, 705-711.

[7] Scarmeas N, Luchsinger JA, Schupf N, Brickman AM, Cosentino S, Tang MX, Stern Y (2009) Physical activity, diet, and risk of Alzheimer disease. JAMA 302, 627-637.

[8] Tolppanen AM, Solomon A, Kulmala J, Kareholt I, Ngandu T, Rusanen M, Laatikainen T, Soininen H, Kivipelto M (2015) Leisure-time physical activity from mid- to late life, body mass index, and risk of dementia. Alzheimers Dement 11, 434-443. e436.

[9] Larson EB, Wang L, Bowen JD, McCormick WC, Teri L, Crane P, Kukull W (2006) Exercise is associated with reduced risk for incident dementia among persons 65 years of age and older. Ann Intern Med 144, 73-81.

[10] de Bruijn RF, Schrijvers EM, de Groot KA, Witteman JC, Hofman A, Franco OH, Koudstaal PJ, Ikram MA (2013) The association between physical activity and dementia in an elderly population: The Rotterdam Study. Eur J Epidemiol 28, 277-283.

[11] Tan ZS, Spartano NL, Beiser AS, DeCarli C, Auerbach SH, Vasan RS, Seshadri S (2017) Physical activity, brain volume, and dementia risk: The Framingham Study. J Gerontol A Biol Sci Med Sci 72, 789-795.

[12] Downey A, Stroud C, Landis S, Leshner AI, eds (2017) Preventing Cognitive Decline and Dementia: A Way Forward, National Academies Press, Washington (DC).

[13] Livingston G, Sommerlad A, Orgeta V, Costafreda SG, Huntley J, Ames D, Ballard C, Banerjee S, Burns A, CohenMansfield J, Cooper C, Fox N, Gitlin LN, Howard R, Kales HC, Larson EB, Ritchie K, Rockwood K, Sampson EL, Samus Q, Schneider LS, Selbaek G, Teri L, Mukadam N (2017) Dementia prevention, intervention, and care. Lancet 390, 2673-2734.

[14] Sabia S, Dugravot A, Dartigues JF, Abell J, Elbaz A, Kivimaki M, Singh-Manoux A (2017) Physical activity, cognitive decline, and risk of dementia: 28 year follow-up of Whitehall II cohort study. BMJ 357, j2709.

[15] Sink KM, Espeland MA, Castro CM, Church T, Cohen R, Dodson JA, Guralnik J, Hendrie HC, Jennings J, Katula J,
Lopez OL, McDermott MM, Pahor M, Reid KF, Rushing J, Verghese J, Rapp S, Williamson JD (2015) Effect of a 24-month physical activity intervention vs health education on cognitive outcomes in sedentary older adults: The LIFE Randomized Trial. JAMA 314, 781-790.

[16] Krell-Roesch J, Pink A, Roberts RO, Stokin GB, Mielke MM, Spangehl KA, Bartley MM, Knopman DS, Christianson TJ, Petersen RC, Geda YE (2016) Timing of physical activity, apolipoprotein E epsilon4 genotype, and risk of incident mild cognitive impairment. J Am Geriatr Soc 64, 2479-2486.

[17] Roberts RO, Geda YE, Knopman DS, Cha RH, Pankratz VS, Boeve BF, Ivnik RJ, Tangalos EG, Petersen RC, Rocca WA (2008) The Mayo Clinic Study of Aging: Design and sampling, participation, baseline measures and sample characteristics. Neuroepidemiology 30, 58-69.

[18] Geda YE, Roberts RO, Knopman DS, Christianson TJ, Pankratz VS, Ivnik RJ, Boeve BF, Tangalos EG, Petersen RC, Rocca WA (2010) Physical exercise, aging, and mild cognitive impairment: A population-based study. Arch Neurol 67, 80-86.

[19] National Center for Health Statistics (U.S.), Moss AJ, Parsons VL (1986) Current estimates from the National Health Interview Survey, United States, 1985. Vital and Health Statistics, Series 10, No. 160. DHHS Pub. No. (PHS) 861588. Public Health Service, Washington, U.S. Government Printing Office, Sept.

[20] Folsom AR, Caspersen CJ, Taylor HL, Jacobs DR, Jr., Luepker RV, Gomez-Marin O, Gillum RF, Blackburn H (1985) Leisure time physical activity and its relationship to coronary risk factors in a population-based sample. The Minnesota Heart Survey. Am J Epidemiol 121, 570-579.

[21] Kokmen E, Smith GE, Petersen RC, Tangalos E, Ivnik RC (1991) The Short Test of Mental Status: Correlations with standardized psychometric testing. Arch Neurol 48, 725-728.

[22] Rey A (1964) L'examen clinique en psychologie, Presses Universitaires de France, Paris.

[23] Wechsler D (1987) Wechsler Memory Scale-Revised, The Psychological Corporation, New York.

[24] Kaplan E, Goodglass H, Weintraub S (2001) Boston Naming Test, Lippincott Williams \& Wilkins, Philadelphia.

[25] Lucas JA, Ivnik RJ, Smith GE, Bohac DL, Tangalos EG, Graff-Radford NR, Petersen RC (1998) Mayo's Older Americans Normative Studies: Category fluency norms. J Clin Exp Neuropsychol 20, 194-200.

[26] Wechsler D (1981) Wechsler Adult Intelligence ScaleRevised, Psychological Corporation, New York.

[27] Reitan RM (1958) Validity of the Trail Making Test as an indicator of organic brain damage. Percept Mot Skills $\mathbf{8}$, 271-276.

[28] Petersen RC (2004) Mild cognitive impairment as a diagnostic entity. J Intern Med 256, 183-194.

[29] Winblad B, Palmer K, Kivipelto M, Jelic V, Fratiglioni L, Wahlund LO, Nordberg A, Backman L, Albert M, Almkvist O, Arai H, Basun H, Blennow K, de Leon M, DeCarli C, Erkinjuntti T, Giacobini E, Graff C, Hardy J, Jack C, Jorm A, Ritchie K, van Duijn C, Visser P, Petersen RC (2004) Mild cognitive impairment-beyond controversies, towards a consensus: Report of the International Working Group on Mild Cognitive Impairment. J Intern Med 256, 240-246.

[30] Charlson ME, Pompei P, Ales KL, MacKenzie CR (1987) A new method of classifying prognostic comorbidity in longitudinal studies: Development and validation. J Chronic Dis 40, 373-383. 
[31] Beck AT, Steer RA, Brown GK (1996) BDI-II, Beck Depression Inventory: Manual, Psychological Corp.; Harcourt Brace, San Antonio, TX; Boston, MA.

[32] Hixson JE, Vernier DT (1990) Restriction isotyping of human apolipoprotein $\mathrm{E}$ by gene amplification and cleavage with HhaI. J Lipid Res 31, 545-548.

[33] Ma DY, Wong CH, Leung GT, Fung AW, Chan WC, Lam LC (2017) Physical exercise helped to maintain and restore functioning in chinese older adults with mild cognitive impairment: A 5-year prospective study of the Hong Kong Memory and Ageing Prospective Study (HK-MAPS). J Am Med Dir Assoc 18, 306-311.

[34] Lautenschlager NT, Cox KL, Flicker L, Foster JK, van Bockxmeer FM, Xiao J, Greenop KR, Almeida OP (2008)
Effect of physical activity on cognitive function in older adults at risk for Alzheimer disease: A randomized trial. JAMA 300, 1027-1037.

[35] Verghese J, Ayers E, Barzilai N, Bennett DA, Buchman AS, Holtzer R, Katz MJ, Lipton RB, Wang C (2014) Motoric cognitive risk syndrome: Multicenter incidence study. Neurology 83, 2278-2284.

[36] St Sauver JL, Grossardt BR, Leibson CL, Yawn BP, Melton LJ, 3rd, Rocca WA (2012) Generalizability of epidemiological findings and public health decisions: An illustration from the Rochester Epidemiology Project. Mayo Clin Proc 87, 151-160. 